\title{
Neural network based prediction of roughing and finishing times in a hot strip mill( ${ }^{(*)}$
}

\author{
V. Colla*, M. Vannucci* and R. Valentini**
}

\begin{abstract}
The paper presents a model based on neural networks which is able to predict the time required to pass the different gauges of a roughing and finishing mill as function of some slab features and process parameters. The final aim of the work is to increase the rolling efficiency while avoiding collisions and queues that cause time and energy losses. Neural networks are suitable to this prediction task as they are particularly able to cope with unknown non linear relationships between input and output variables. Moreover they can learn from real industrial data and therefore do not require prior assumptions or mathematical modelling of the process and transferability is ensured by the possibility to use different databases coming from different rolling mills. In the paper, two different kinds of neural network-based models have been proposed, their performances have been discussed and compared.
\end{abstract}

\section{Predicción basada en redes neuronales del tiempo de procesamiento de los trenes desbastador y laminador en una instalación de laminación en caliente}

Resumen

Palabras clave
En este artículo se presenta un modelo basado en redes neuronales capaz de predecir el tiempo necesario para pasar las diferentes galgas de un tren desbastador y acabador en función de ciertas características del desbaste y parámetros de proceso. El objetivo final es aumentar la eficacia de la laminación evitando colisiones y colas que provoquen pérdidas de tiempo y energía. Se propone utilizar para esta tarea redes neuronales por su capacidad de predicción en aquellos casos en los que existen relaciones no lineales desconocidas entre las variables de entrada y las de salida. Además, son capaces de aprender de datos industriales reales y, por tanto, no requieren suposiciones previas o modelos matemáticos del proceso, estando la transferibilidad asegurada ya que es posible utilizar distintas bases de datos procedentes de diferentes trenes de laminación.

Laminación en caliente; Desbaste; Bobina; Ritmo de laminado; Red neuronal.

\section{INTRODUCTION}

In modern rolling mills, efficiency is strictly related to the possibility of correctly knowing when the different manufacturing stages are completed, in order to avoid bottlenecks and save time and energy.

Such optimisation effort begins from the reheating furnaces, where mill pacing control (MPC) system are designed in order to abbreviate the discharging interval between two slabs without triggering collision of two slabs ${ }^{[1}$ and 2$]$. To avoid the collision, it is necessary to forecast the discharging time for the slab transferred to mill line, to monitor all strips in the process, and to give an alarm when collision is possible. Based on kinematics, supported by data of plant equipment and setup data, the calculation of strip transmission gets the moving track of strip tail and head. According to the calculation result, the possible collision position can be forecasted. The position varies with different equipment capacities,

\footnotetext{
(•) Trabajo recibido el día 27 de noviembre de 2008 y aceptado en su foprma final el día 26 de octubre de 2009.

* Scuola Superiore Sant'Anna, Polo Sant'Anna Valdera, Laboratorio PERCRO, Steel and Industrial Automation Division, Viale Rinaldo piaggio 34, 56025, Pontedera (PI), ITALY. colla\{mvannucci\}@sssup.it.

** Università di Pisa, Facoltà di Ingegneria, Dipartimento di Ingegneria Chimica, Chimica Industriale e Scienza dei Materiali, Via Diotisalvi 2, Pisa, ITALY. r.valentini@ing.unipi.it.
} 
different product sizes and operator's interventions. For MPC strategy application, each production line needs coordination, no matter what is the material flow allocation of a whole plant or of a single section. Accordingly, schedule systems are developed and simulations are also performed in order to test new strategies without affecting the production cycle (see for instance $\left.{ }^{[3]}\right)$.

In the past, the schedule software was produced on the basis of realistic process, which had limits on application to all processes. An alternative to this approach is provided by Neural Networks $(\mathrm{NN})^{[4]}$ based-prediction, that can be adapted to different production lines thanks to the self-learning capability of neural networks, which are able to adapt their internal parameters through automatic procedures exploiting data form the field.

The application of $\mathrm{NN}^{[4]}$ is receiving increasing attention in the steelmaking field and is surely not new in the sector of hot rolling ${ }^{[5]}$, in particular for fault detection ${ }^{[6]}$, as well as of other soft-computing techniques ${ }^{[7]}$. Neural networks have also successfully been applied in prediction of product properties ${ }^{[8-11]}$ as well as process simulation and control ${ }^{[12}$ and 13].

The availability of a considerable amount of data is a quite crucial point for the implementation of $\mathrm{NN}$ based models, as well as for optimization of more traditional ones, but this is no more a problem, as the increasing degree of automation in the steelmaking plants and the continuously enlarging possibilities of modern computers and tools for storing data ${ }^{[14]}$ offers to researchers the possibility of extracting information and even new knowledge from all such data, provided that suitable data processing techniques are exploited and used jointly with the available comprehension of the processes occurring on the plant from which the data are extracted. Statistical analysis of the data collected from the plants has become a very important field of steelmaking research, even more important with respect to other industrial fields, if one considers the difficulty in observing and monitoring the physical and chemical processes involved in the steelmaking practice. The importance of statistical analysis has been already underlined in recent literature (see for instance ${ }^{[15]}$ ) and statistical analysis has been frequently coupled with NN.

In the present paper, a particular mill pacing problem, different from the typical one that was above presented, has been faced through $\mathrm{NN}$, namely the prediction of the total roughing time and of the time required for passing the first gauge of the finishing mill. The reason for this investigation was the need to increase the rolling efficiency and decrease the total rolling time by saving both time and energy. Actually the slabs that are subsequently rolled can differ in steel grade and other features, thus their rolling process is different in both time and required energy. The time required for the roughing process is in average but not always smaller than the finishing time. Thus it can happen that a slab exits from the roughing mill while the rolling of the previous coil is still ongoing and thus either a collision occurs or the second slab remains in queue and its temperature decreases, which makes its successive rolling more difficult. On the other hand, if too much time is spent between two successive slabs inputs to the roughing time, the first rolled coil can exit from the finishing mill far before the second slab is output from the roughing mill, with a consequent time and energy loss. The final aim of the work where the present contribution is inserted is the design of a strategy that inputs a slab to roughing mill exactly at the time that will allow it to arrive at the entrance of the finishing mill when the rolling of the previous coil is just terminated.

The work was organized in two phases, the first one focused on the data analysis, the investigation of the causes affecting the time required for passing the roughing mill and on the prediction of such time, while the second phase concerned the prediction of the finishing time.

\section{PROBLEM DESCRIPTION AND DATA ANALYSIS}

A database containing about 50.000 data directly coming from a real industrial context has been used for the development of the neural models. Such database has been preprocessed and unreliable data have been filtered out. In particular data outliers have been detected and subsequently eliminated from the database by means of a method based on the use of fuzzy logic which aims at spotting all those data whose position in the space is not in line with the standards so as that their presence is likely due to measure errors, sensors failures or similar causes ${ }^{[16]}$.

From the analysis of the available data and from the indications of expert people of the steel plant, it was pointed out that the main variables concerning the overall roughing process that affect the roughing time are: initial and final slab width, initial and final slab thickness, initial slab length, steel quality and previewed slab temperature. This selection was confirmed as well by a simple statistical analysis performed on the available data ${ }^{[17]}$.

During the roughing process, each slab passes subsequently through 6 different rolling gauges as depicted in figure 1 . Thus the whole roughing process can be divided into 6 different sub-phases; each phase 


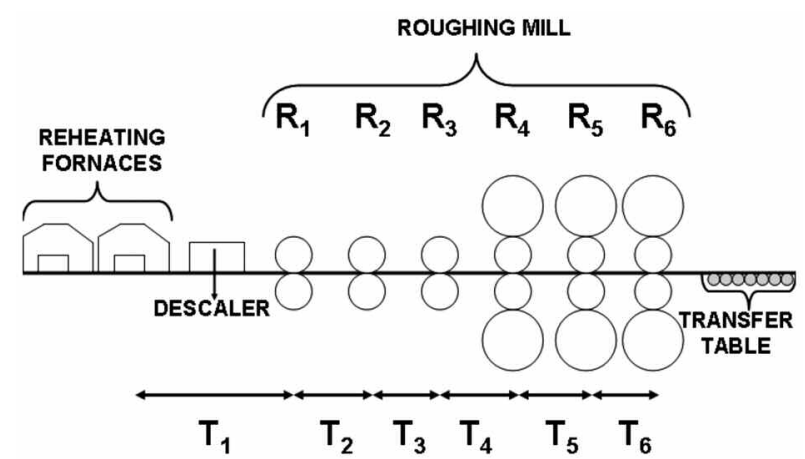

Figure 1. schematic description of the roughing mill.

Figura 1. Esquema de un tren desbastador.

needs a specific completion time. Our aim is the prediction of these 6 completion times since their sum corresponds to the total roughing time.

The available industrial database contains the 6 measurements of the completion times that are the variables to be predicted (indicated in the following as $T_{1}, . ., T_{6}$ ).

\section{NEURAL NETWORK-BASED PREDIC- TORS OF THE ROUGHING TIME}

Different kinds of neural networks and two main predicting structures have been tried for the prediction of the times required for passing the 6 different roughing gauges.

The first and more traditional structure of the predictor uses 6 feed-forward neural networks one for each single roughing time and exploits as inputs the variables listed in the previous subsection. By exploiting this structure, all the 6 time values are simultaneously predicted.
In order to increase the prediction performance a second version of the predictor was experimented, where some more variables were added to the input vector and, in particular, while predicting a certain roughing time also all the previously predicted roughing times are exploited as inputs for the neural network. For instance, while predicting $\mathrm{T}_{3}$ the input vector will be formed by: slab width; slab length; mill reduction; slab thickness; slab temperature and the predicted $T_{1}$ and $T_{2}$. By exploiting such predictor structure, the 6 time values are predicted not simultaneously but in their original order, thus this architecture is indicated as "sequential predictor". In both the predictor structures several neural paradigms have been tested for implementing the neural predictor. The best performing one appears to be a multi-layer perceptron with a single hidden layer in which neurons are characterised by an hyperbolic tangent activation function.

The performance of the different prediction algorithms where evaluated in terms of absolute and relative error and compared with the performance of the predictor that is currently used in the normal operating practice. Table I reports the absolute mean error obtained by means of the basic and the sequential neural predictors in terms of absolute error and allows a comparison with the prediction algorithm adopted until now by the steelmaking plant. The results refer to 10 cross validation tests performed on the filtered original database, including 47000 observation subdivided each time into a training and a validation set containing the $75 \%$ and $25 \%$ of the available observations respectively.

The last rows reports also the mean absolute value of the times to be predicted, in order to allow an evaluation of the relative error. The pre-existing method used for this estimation consists of a simple linear model developed by the steel plant personnel and involving some of the variables selected for the neural networks based model and some statistics on the average working times of machinery at certain

Table I. Performance of the different prediction methods in terms of absolute mean errors (time values are reported in s)

Tabla I. Rendimiento de los diferentes métodos (tiempo en s)

\begin{tabular}{lcccccc}
\hline Prediction algorithm & $\mathbf{T}_{\mathbf{1}}$ & $\mathbf{T}_{\mathbf{2}}$ & $\mathbf{T}_{\mathbf{3}}$ & $\mathbf{T}_{\mathbf{4}}$ & $\mathbf{T}_{\mathbf{5}}$ & $\mathbf{T}_{\mathbf{6}}$ \\
\hline Basic & 1.56 & 0.55 & 1.22 & 1.32 & 1.38 & 5.11 \\
Sequential & 1.56 & 0.52 & 1.21 & 1.33 & 1.29 & 4.90 \\
Pre-existing method & 2.61 & 4.26 & 2.25 & 2.34 & 1.92 & 4.97 \\
Measured average time value & 49.9 & 26.6 & 32.4 & 28.8 & 31.6 & 40.9 \\
\hline
\end{tabular}


conditions. The coefficient used in such model were calculated by means of linear multivariate regression.

From the obtained results it turns out that the performance obtained by the basic neural prediction method is by itself very satisfactory, as a reduction of about $40 \%$ with respect to the traditional method is obtained on all the times to be predicted, with the exception of $T_{6}$. In this latter case, the basic neural predictor does not outperform the traditional predictor.

The adoption of the sequential structure slightly improves the goodness of the prediction, especially for what concerns $T_{5}$ and $T_{6}$. The worse performance in the prediction of $T_{6}$ was expected, as many variables can affect such time value and not all of them are measurable. To sum up, by adopting the best performing prediction method, i.e. the sequential neural predictor, the absolute mean prediction error in the prediction of the total time for performing the roughing process is about 10 s while the mean duration of the roughing process is of about 3:10 min, which means a relative error of $5.2 \%$.

\section{NEURAL NETWORK-BASED PREDIC- TION OF THE FINISHING TIME}

In order to improve the efficiency of the automated control of the hot rolling mill, also a module for the prediction of the time necessary for the finishing mill manufacturing was developed.

The time needed for the passage of the steel strip from the finishing mill is the sum of the time needed for the passage of the strip through each of the 6 stands that compose the machinery. Nevertheless the technical personnel working on the plant considers important for the control of the mill mainly the time needed by the first stand as it plays the role of "bottle-neck" of the whole process. Thus the work was focused on the prediction of the working time of the first stand of the finishing mill.

The basic idea is to use for such prediction a set of variables that are available before the start of the process; once the prediction is available, it will be used for optimizing the process. The variables that have been selected comprise: strip characteristics, process settings and strip properties measured before the entrance in the finishing mill. The final set of measures that have been investigated for the prediction is the result of various discussions with industrial experts. It must be underlined that in the choice of the variables a priority criteria which has been adopted consists in their availability and reliability, in facts the variables pointed out by industrial people are always present in the database, always measured and their measure is very reliable. The selected variables are shown in the table II. Among these variables the nominal finishing mill thickness has been included due to the high number (more than 100) different values it has within the database. This aspect impeded to use such variable as a splitting criteria for creating a different neural network for each distinct value.

The original database, once filtered in order to eliminate unreliable data, contains about 20000 records of which $75 \%$ have been used for the tuning of the model and the remaining $25 \%$ for its validation.

A model based on a 2 layers feed-forward neural network for the prediction of finishing mill time has been built. An exhaustive set of tests considering all the possible combinations of input variables have been performed considering the indications provided by industrial experts in order to find those allowing the best prediction of our target variable, the time necessary for passing the first stand of the finishing mill. For this purpose different structures of neural networks have been employed with a number of hidden neurons varying between 6 and 20. More in detail 32 different combinations involving the 6 variables suggested by the experts were tested. In all the tests the variable "strip length" has been included due to its strict relationship with the target variable. The results of these tests are presented in table III in terms of mean \% error.

Table II. Variable that mostly affect the finishing time

Tabla II. Variables de mayor influencia sobre el tiempo del procesamiento

\begin{tabular}{ll}
\hline \multicolumn{1}{c}{ Group } & \multicolumn{1}{c}{ Variables } \\
\hline Strip characteristics & Strip length; steel quality \\
Process settings & Nominal strip width and thickness \\
Measured strip properties & Temperature at the exit of roughing mill; width at the exit of roughing mill \\
\hline
\end{tabular}


NEURAL NETWORK BASED PREDICTION OF ROUGHING AND FINISHING TIMES IN A HOT STRIP MILL PREDICCIÓN BASADA EN REDES NEURONALES DEL TIEMPO DE PROCESAMIENTO DE LOS TRENES DESBASTADOR Y LAMINADOR EN UNA INSTALACIÓN DE LAMINACIÓN EN CALIENTE

Table III. Results obtained by NN based methods for the prediction of finishing time

Tabla III. Resultados obtenidos mediante redes neuronales para la predicion del tiempo del laminador

\begin{tabular}{rll} 
Hidden Neurons & \multicolumn{1}{c}{ Inputs } & Err \% \\
\hline 8 & Strip length, nominal thickness & 7.62 \\
8 & Strip length, nominal thickness, bar thickness & 7.37 \\
12 & Strip length, nominal thickness, bar thickness & 7.2 \\
12 & Strip length, nominal thickness, temperature mill exit & 7.14 \\
12 & Strip length, nominal thickness, bar thickness, temperature mill exit & 6.6 \\
18 & Strip length, nominal thickness, bar thickness, temperature mill exit & 6.5 \\
\hline
\end{tabular}

Due to the reduced size of data and variables the number of tests to be performed for the definition of the most suitable input combination allowed an exhaustive search, otherwise, in presence of a higher number of data or a potential variables to be considered some methods for variables selection ${ }^{[18]}$ or feature extraction ${ }^{[19]}$ could be necessary.

The model that considers all variables is the best performing one, on the other hand the tests that were performed by introducing the information about the steel quality (grouping similar strips and generating ad hoc models) did not improve the results probably due to the high correlation of the other considered variables which abated the contribution in terms of additional information provided by the steel quality.

The model obtained a $6.5 \%$ average error that means an average absolute error of $4 \mathrm{~s}$ for a process that takes $70 \mathrm{~s}$. The error distribution of the best performing neural model is described in the figure 2 , while figure 3 depicts how measured versus predicted finishing time are distributed. Furthermore the number of samples with high error is about the $5 \%$ of the whole observations: such figure is acceptable according to industrial constraints.

\section{NEURAL NETWORK-BASED MODELS IMPLEMENTATION}

A software implementation of systems described in this section for the prediction of roughing and finishing mill working time was developed by using the Matlab programming language and including a user friendly interface which is shown in figures 4 and 5, respectively. These interfaces allow the user to perform single predictions by inserting one by one the required inputs; otherwise user can perform a multiple prediction by indicating to the program the MSExcel file containing the inputs concerning

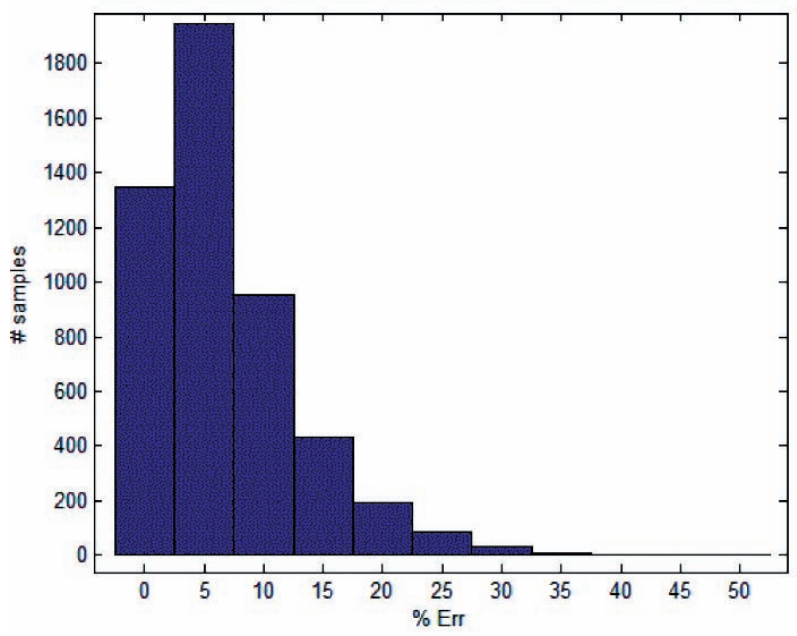

Figure 2. Bar diagram showing per cent error distribution for the prediction of first stand finishing mill working time.

Figura 2. Diagrama de barras con la distribucion del porcentaje de error en la estimación del tiempo de trabajo de la primera posición del tren laminador.

multiple samples: in this case the software will provide working time predictions via an external ASCII file.

\section{CONCLUSIONS AND FUTURE WORK}

A method based on neural networks has been presented for the prediction of the time required to pass the roughing and finishing mills as a function of the slab and strip characteristics and measured properties and of the process settings. Such prediction is useful in order to improve the efficiency of the overall rolling process, by avoiding bottlenecks and 


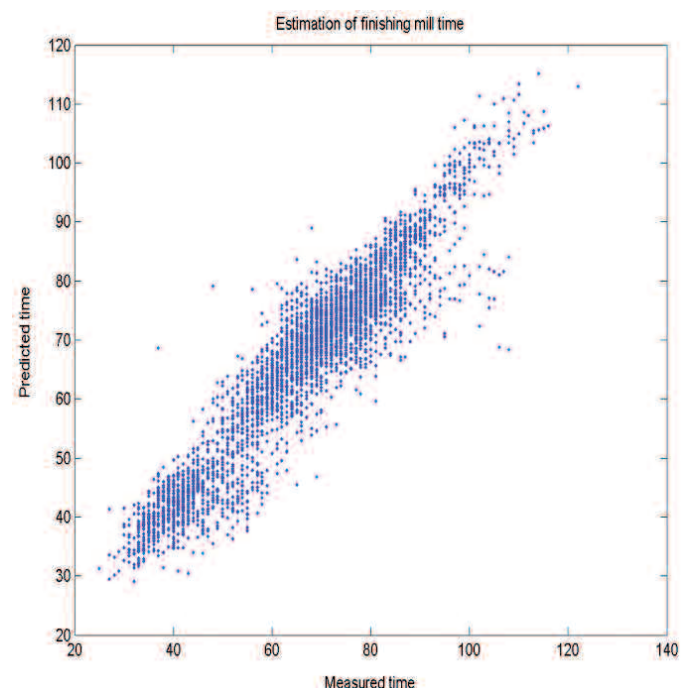

Figure 3. Absolute error distribution for the prediction of first stand finishing mill working time.

Figura 3. Distribución de el error absoluto cometido en la predicción del tiempo de trabajo de la primera posición del tren laminador.

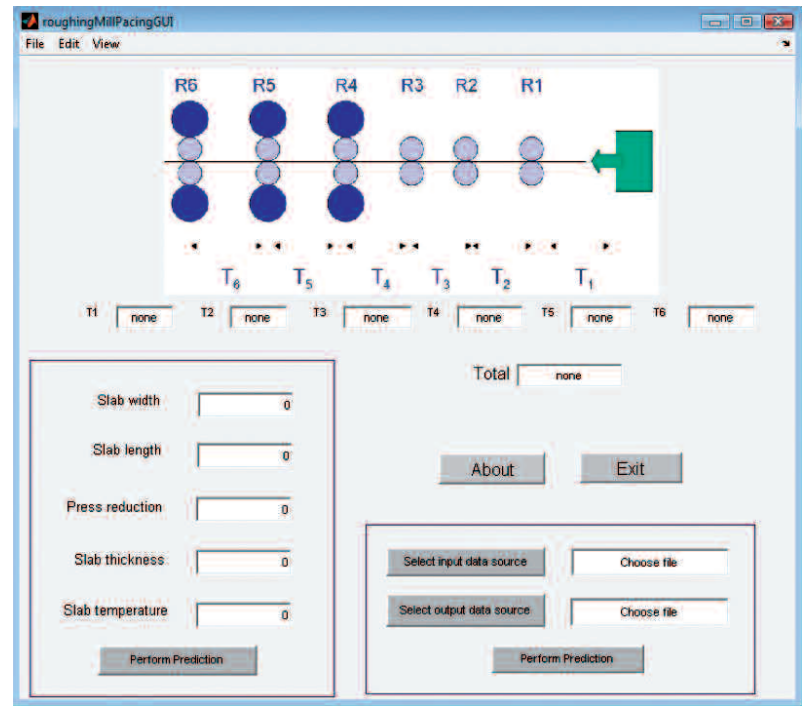

Figure 4. The roughing mill working time prediction software interface.

Figura 4. Interfase del programa de cálculo del tiempo de trabajo del tren desbastador.

saving time and energy. The performance of the different neural networks that were applied have been discussed and compared and the best ones have been selected leading to the final development of a software tool including a user friendly interface which allows an easy use from human operators. Neural networks

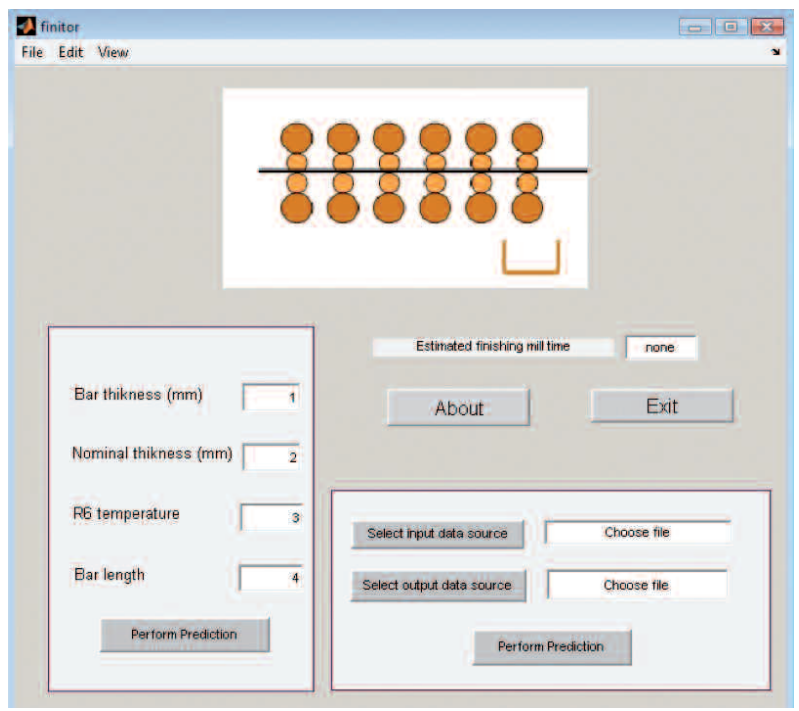

Figure 5. The finishing mill working time prediction software interface.

Figura 5. Interfase del programa de cálculo del tiempo de trabajo del tren laminador.

sensibly increased the predictive performance of the predictor leading to interesting results which were not obtained by the previously used method based on a linear equation. Furthermore the developed tool can provide reliable predictions in real-time and can automatically adapt to future productions by retraining the neural networks involved granting the lasting usability of the software. Thanks to these facilities the software can adapt to any future production cycle and can be used and maintained by any operator without needing any prior knowledge of the employed technologies.

Future work will concern the on-site implementation of the presented model, in order exploit it in the normal operating conditions.

\section{Acknowledgements}

The work described in the present paper was developed within the project entitled "Integrated process control \& diagnosis system for hot rolling mills based on comparison of physical data $\&$ mathematical process models by using artificial intelligence" (Contract No RFS-CR-03038) that has received funding from the Research Fund for Coal and Steel of the European Community. The sole responsibility of the issues treated in the present paper lies with the authors; the Commission is not responsible for any use that may be made of the information contained therein. 


\section{REFERENCES}

[1] S. Sasaka, Y. Kozaki, Y. Chida, T. Kotake, F. Fukuda and T. Satoh, ISIJ Int. 30 (1990) 161166.

[2] O. Michinori, 111th ISIJ Meeting, Vol. 72 (4), Tokyo, Japan, 1986, pp. S330.

[3] J. Katzberg and Q. Li, Proc. IEEE Communications, Power, and Computing Conf. WESCANEX'95. Vol. 2, Winnipeg, Man., Canada, 1995, IEEE Service Center, Piscataway NJ, pp. 344-348.

[4] Y.S. Kim, B.J. Yum and M. Kim, Proc. 2001 Int. Joint Conf. Neural Networks IJCNN 2001, Washington DC, USA, 2001, pp. 2800-2804.

[5] H. Tamler and I. Jaeckel, BRITE/EURAM-project BE96-3061.

[6] Y. Bissessur, E.B. Martin, A.J. Morris and P. Kitston, IEE Proc. Control Theory Appl., Vol. 147, No. 6, 2000, IET, Stevenage, UK, 2001, pp. 633-640.

[7] S. Guan, H.X. Li and S.K. Tso, IEEE Trans. Contr. Syst. Technol. 9 (2001), 348-356.

[8] C. Dumortier and P. Lehert, ISIJ Int. 39 (1999) 980-985.

[9] R. Valentini, V. Colla, M. Sgarbi and L.M.
Reyneri, Rev. Metal. Madrid, Vol. Extr. (2005) 314-317.

[10] D. Dunne, H. Tsuei and Z. Sterjovski, ISIJ Int. 44 (2004) 1599-1607.

[11] J. Warde and D.M. Knowles, ISIJ Int. 39 (1999)1006-1014.

[12] R. Valentini, V. Colla and M. Vannucci, Rev. Metal. Madrid 40 (2004) 416-419.

[13] J.M. Vitek, ISIJ Int. 39 (1999) 1088-1095.

[14] J. Aylen, Ironmak. Steelmak. 31 (2004) 466.

[15] R.P. Bhagat, H.S. Ray and S.K. Gupta, ISIJ Int. 31 (1991) 669-676.

[16] S. Cateni, V. Colla and M. Vannucci, AIA 2007 Conf., Innsbruck, Austria, 2007, Vladan Devedzic (Ed.), IASTED/ACTA Press, Calgary, Canada, 2007, pp. 605-610.

[17] T. T. Soong, Fundamentals of probability and statistics for engineers, John Wiley \& Sons Ed., Chichester. England, 2004.

[18] D. A. Sofge and D. L. Elliott, Proc. Conf. Neural Networks $\mathcal{E}$ Brain (NN\&B'98-Beijing), Beijing, China 1998.

[19] I. Guyon, S. Gunn, M. Nikravesh and L.A. Zadeh, Feature extraction: foundations and applications", Springer-Verlag, New York, USA, 2006. 